\title{
Detection of extended spectrum B-lactamase in E. coli from clinical samples
}

\author{
Ansam M. Hamdoon \\ Department of Microbiology, College of Medicine, University of Mosul.
}

(Ann. Coll. Med. Mosul 2011; 37 (1 \& 2): 122-128).

Received: $17^{\text {th }}$ May 2011; Accepted: $10^{\text {th }}$ Oct 2011.

\begin{abstract}
Objectives: 1- To study the frequency of ESBL (extended spectrum beta lactamase) among E. coli clinical isolates. 2- To determine the antibiotic profile for the isolates. 3- To determine the difference between the antimicrobial susceptibility of the ESBL producing E. coli and non producers.

Methods: A 4-months review of patients from three different hospitals who were diagnosed to have genitourinary tract infections with $\mathrm{E}$. coli. These isolates were identified and assessed for their production of B-lactamase, and their antibiotic susceptibility to 21 different antimicrobial agents was determined.

Results: Out of the total $136 \mathrm{E}$. coli isolates, $58.82 \%$ were found to be ESBL producers. The most effective antimicrobial agent against the isolates was amikacin $(85 \%)$, followed by ciprofloxacin $(67.6 \%)$, while all the isolates were fully resistant to penicillin, cephradine, cephalothin and carbencillin. Multi-drug resistance (MDR) were found to be more among the ESBL producers. There was a statistical association between the production of B-lactamase and the resistance to Amikacin, nitrofurantoin, levofloxacin, kanamicin, nalidixic acid, gentamicin, piperacillin, cefotaxime and cephalexin.
\end{abstract}

Conclusions: This study shows that E. coli recovered from clinical specimens produce B-lactamase in high percentage and are resistant to penicillins and most cephalosporins. In addition, the MDR was higher among the B-lactamase producers. Therefore, determination of B-lactamases production, antimicrobial sensitivity of the isolates and strict antibiotic policy should be adopted in hospitals to take steps for reducing the bacterial resistance.

الخلاصة

الأهداف: دراسة وجود أنزيم البيتا لاكتاميز في العزلات السريرية للشريشيات القولونية وتحديد حساسيتها للمضادات

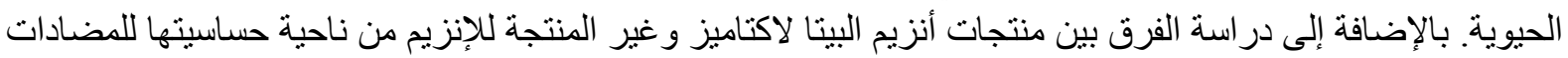
الحبوية. طرق العمل: كانت مدة جمع العينات ع أثنهر من مرضى من ثناث مستشفيات مختلفة. نم عزل الثريشيات القولونية عندهم

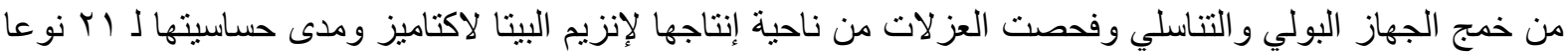
مختلفا من المضادات الحيوية.

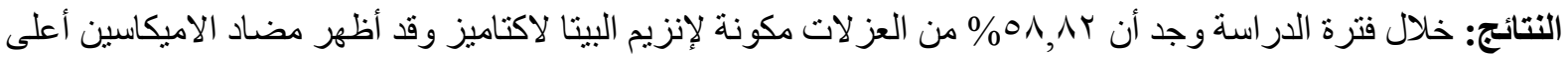

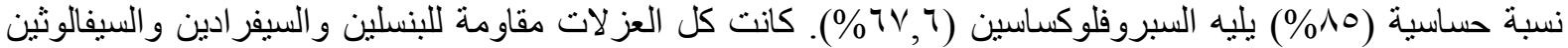

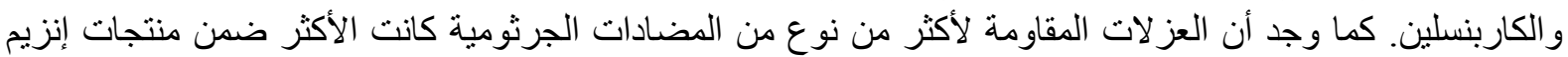

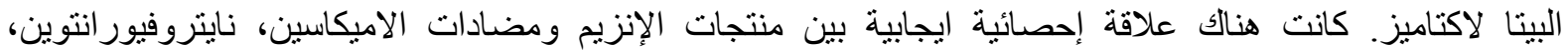
ليفو فلوكساسين، كانامايسين، ناليدكسيك اسيد، جنتامايسين، بيير اسيللين، سيفوتاكسيم وسيفاليكسين. 


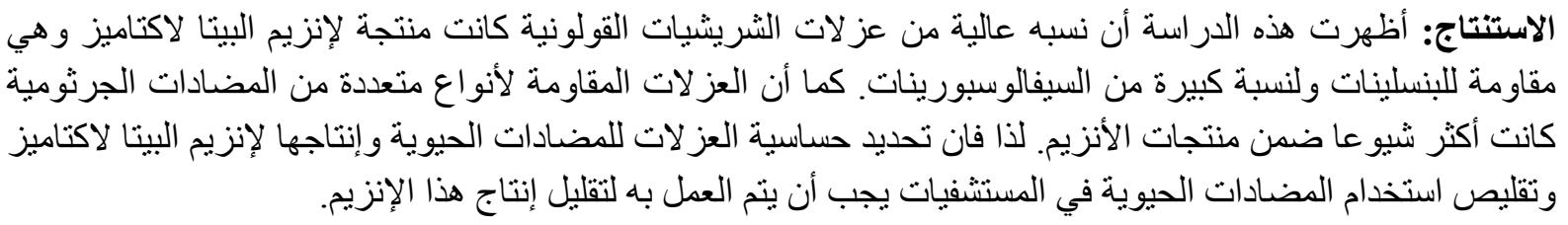

E xtended spectrum $\quad \beta$-lactamases (ESBLs) producing Enterobacteriaceae are a worldwide growing and important problem in hospital practice, which is tied to the extensive use of broad spectrum antibiotics. $^{(1,2)}$

The most prevalent mechanisms of bacterial resistance among gram negative bacilli are the production of $\beta$-lactamases (chromosomal or plasmid mediated), alteration in the penicillin binding proteins, outer membrane permeability, and combination of multiple mechanisms. ${ }^{(3,4)}$

Beta-lactam antibiotics are among the safest and most frequently prescribed antimicrobial drugs in the world ${ }^{(5)}$. The most important mechanism of bacterial resistance to B-lactam antibiotics is the production of $\beta$-lactamase enzymes which can hydrolyze virtually all $\beta$ lactam antibiotics except cephamycins and carbapenems, and are generally inhibited by $\beta$-lactamase inhibitors such as clavulanic acid, sulbactam, or tazobactam. ${ }^{(6-8)}$

To date, a wide variety of $\beta$-lactamase enzymes continue to be identified, which may be partly attributed to the wide use of $\beta$-lactam antibiotics. ES $\beta$ LS are one of the most common type of $\beta$-lactamase enzymes. ${ }^{(2)}$

ESBL producing strains have emerged among the Enterobacteriaceae, prominently in Escherichia coli and Klebsiella pneumoniae. They were first isolated in Germany in 1983, and a rapid dissemination has been responsible for numerous outbreaks of infections throughout the world ${ }^{(9)}$. The prevalence of ESBL-producing Enterobacteriaceae specially $\mathrm{E}$. coli and $\mathrm{K}$. pneumonia, among clinical isolates, varies according to the geographical distribution. Moreover, the increase of ESBL mediated resistance amongst $\mathrm{E}$. coli and Klebsiella isolates renders this problem a major public health threat. ${ }^{(10)}$
The emergence of ESBL has increased the possibility that traditional empiric antimicrobial regimens may be ineffective, resulting in limitation of therapeutic options and making urinary tract infection (UTI), which remains the most common bacterial infection in human populations, and other infections difficult to treat. $^{(1,11)}$

In genital tract infections E. coli which normally inhabits the rectum can cause infection if spread to the vagina in which the normal balance of bacteria may be disrupted, resulting in the overgrowth of harmful bacteria at the expense of protective bacteria.

Furthermore, antibacterial agents such as trimethoprim-sulphamethoxazole, aminoglygosides, flouroquinolones, tetracyclins and chloramphenicol are often co-transferred on a resistance plasmid resulting in multidrug resistance $^{(7)}$. However, carbapenems are the treatment of choice for serious infections due to ESBL producing organisms ${ }^{(8)}$.

The National Committee for Clinical Laboratory Standards (NCCLS) recommends ESBL screening methods and confirmatory tests, because delay in the detection and reporting of ESBL production is associated with prolonged hospital stay, increased morbidity, mortality, and health care costs ${ }^{(5)}$.

The aims of this study are to:

1. Study the frequency of $\beta$-lactamase and ESBL among E. coli recovered from urinary tract and genital tract infections.

2. Study the antibiotic susceptibility pattern and multiple drug resistant E. coli in these patients.

3. Evaluate the difference between the antimicrobial susceptibility patterns of $\beta$ lactamase producing $E$. coli and non producers. 


\section{Materials and methods}

This study was conducted in the Microbiology Laboratory, Department of Microbiology, College of Medicine, University of Mosul.

A total of $136 \mathrm{E}$. coli isolates (112 UTI and 24 genital tract infections) were collected from patients attending Al-Khansa, Al-Batool and Ibn-sena Teaching Hospitals. The period of sample collection was between September 2010 and December 2010. The identification of the isolates was based on morphological features and standard biochemical tests ${ }^{(12)}$.

All the isolates were tested for their susceptibility to 21 selected antibacterial agents using the standard disc diffusion method $^{(12)}$. A sterile cotton swab soaked in the bacterial suspension in Muller Hinton broth was used to inoculate the organisms onto the surface of Muller Hinton agar plates, then the antimicrobial discs were applied and the plates were incubated at $37 \mathrm{C}^{\circ}$ for 24 hours. The resultant inhibition zone diameter for each disc was measured and compared with the control measure ${ }^{(13)}$. The used antibacterial discs were: penicillin $10 \mathrm{U}$, levofloxacin $5 \mu \mathrm{g}$, nalidixic acid $30 \mu \mathrm{g}$, nitrofurantoin $100 \mu \mathrm{g}$, gentamicin $10 \mu \mathrm{g}$, ticarcillin $75 \mu \mathrm{g}$, cefixime $5 \mu \mathrm{g}$, ampicillin 10 $\mu \mathrm{g}$, amikacin $30 \mu \mathrm{g}$, cephalexin $30 \mu \mathrm{g}$, cefoxitin $30 \mu \mathrm{g}$, cefotaxime $10 \mu \mathrm{g}$, kanamycin $30 \mu \mathrm{g}$, cloxacillin $10 \mu \mathrm{g}$, ciprofloxacin $5 \mu \mathrm{g}$, cephradine $30 \mu \mathrm{g}$, enrofloxacin $5 \mu \mathrm{g}$, cephalothin $30 \mu \mathrm{g}$, carbencillin $25 \mu \mathrm{g}$, ceftriaxone $10 \mu \mathrm{g}$ and piperacillin $30 \mu \mathrm{g}$ (Bioanalyse.UK). The interpretation of the results was as recommended by NCCLS.

For the detection of $\beta$-lactamase production, both the rapid iodometric tube method and ESBL activity were tested. In the latter method (ESBL), the double disc synergy test was performed using ceftriaxone and a combination disc of amoxicillin $20 \mu \mathrm{g}$ and clavulanic acid $10 \mu \mathrm{g}^{(11)}$.

Statistical analysis was performed using chi square test where appropriate, and $\mathrm{P}$ value < 0.05 was considered significant.

\section{Results}

In the current study the $\beta$-lactamase enzyme production was detected in the isolated $\mathrm{E}$. coli from urinary tract and genital tract (Figure1). Out of the total 136 tested E. coli, $80(58.8 \%)$ were found to be ES $\beta$ L producers (Figure 2).

There was no statistical association between the production of $\beta$-lactamase enzyme and the source of isolation (UTI and genital tract infection) $\mathrm{P}>0.05$.

The antibiogram profile of the $\mathrm{E}$. coli isolates was determined against a panel of 21 antimicrobial agents. The highest sensitivity percentage was noted in case of amikacin $(85.3 \%)$ followed by ciprofloxacin, enrofloxacin, nitrofurantoin and levofloxacin $(67.6 \%, \quad 66.2 \%, \quad 64.7 \%$ and $58.8 \%$ respectively). In addition, all the isolates were fully resistant to penicillin, cephalothin, cephradine and carbenicillin (Table 1).

The sensitivity to certain antibiotics was statistically decreased $(P<0.05)$ with the production of $\beta$-lactamase enzyme particularly in case of amikacin, nitrofurantoin, levofloxacin, kanamicin, nalidixic acid, gentamicin, ticarcillin, piperacillin, cefotaxime and cephalexin (Table 2).

Broad spectrum resistance, which is defined as the resistance to ampicillin or cephalothin was present in the current work for all the isolates, apart from two $(98.5 \%)^{(5)}$.

Extended spectrum beta lactam resistant E. coli, is defined as resistance of bacteria to ceftriaxone, which was observed in 114 isolates $(83.8 \%)^{(5)}$.

The MDR ESBL was considered as resistance to 3 of the following 4 antibiotic groups: trimethoprim- sulphamethxazole, aminoglycosides (amikacin or gentamicin), fluoroquinolones (ciprofloxacin, norfloxacin, or nalidixic acid), and nitrofurantoin. This MDR was detected in 34 isolates (25\%) and were all $\beta$-lactamase producers, hence, a coresistance to non $\beta$-lactam antibiotics was observed more with ESBL producing E. coli ${ }^{(5)}$. 
Table (1): The antimicrobial sensitivity of E. coli isolates from UTI and genital tract infections.

\begin{tabular}{|l|c|c|c|}
\hline \multicolumn{1}{|c|}{$\begin{array}{c}\text { Antimicrobial } \\
\text { Agents }\end{array}$} & $\begin{array}{c}\text { UTI } \\
\text { No.(\%) }\end{array}$ & $\begin{array}{c}\text { GTI } \\
\text { No.(\%) }\end{array}$ & $\begin{array}{c}\text { Total } \\
\text { No.(\%) }\end{array}$ \\
\hline Amikacin & $94(83.9)$ & $22(91.7)$ & $116(85.3)$ \\
\hline Ciprofloxacin & $72(64.3)$ & $20(83.3)$ & $92(67.6)$ \\
\hline Enrofloxacin & $68(60.7)$ & $22(91.7)$ & $90(66.2)$ \\
\hline Nitrofurantoin & $76(67.8)$ & $12(50)$ & $88(64.7)$ \\
\hline Levofloxacin & $66(58.9)$ & $14(58.3)$ & $80(58.8)$ \\
\hline Kanamicin & $46(40)$ & $14(58.3)$ & $60(44.1)$ \\
\hline Nalidixic acid & $40(35.7)$ & $8(33.3)$ & $48(35.3)$ \\
\hline Gentamicin & $36(32.1)$ & $8(33.3)$ & $44(32.4)$ \\
\hline Ticarcillin & $22(19.6)$ & 0 & $22(16.2)$ \\
\hline Ceftriaxone & $16(14.3)$ & $6(25)$ & $22(16.2)$ \\
\hline Cefixime & $10(8.9)$ & $6(25)$ & $16(11.8)$ \\
\hline Piperacillin & $14(12.7)$ & 0 & $14(10.3)$ \\
\hline Cefotaxime & $8(7.1)$ & 0 & $8(5.9)$ \\
\hline Cephalexin & $8(7.1)$ & 0 & $8(5.9)$ \\
\hline Cefoxitin & $4(3.6)$ & 0 & $4(2.9)$ \\
\hline Cloxacillin & $2(1.8)$ & 0 & $2(1.5)$ \\
\hline Ampicillin & $2(1.8)$ & 0 & $2(1.5)$ \\
\hline Penicillin & 0 & 0 & 0 \\
\hline Cephradine & 0 & 0 & 0 \\
\hline Cephalothin & 0 & 0 & 0 \\
\hline Carbenicillin & 0 & 0 & 0 \\
\hline
\end{tabular}

Table (2): The antimicrobial susceptibility percentages of ESBL producing and non-producing E. coli.

\begin{tabular}{|l|c|c|c|c|c|c|}
\hline \multirow{2}{*}{$\begin{array}{c}\text { Antimicrobial } \\
\text { Agent }\end{array}$} & \multicolumn{2}{|c|}{ B-lactamase producer } & \multicolumn{2}{c|}{$\begin{array}{c}\text { B-lactamase } \\
\text { non -producer }\end{array}$} & \multirow{2}{*}{$\begin{array}{c}\text { Total } \\
\text { sensitive }\end{array}$} & \multirow{2}{*}{ P-value } \\
\cline { 2 - 5 } & Sensitive & Resistant & Sensitive & Resistant & & \\
\hline Amikacin & 75 & 25 & 100 & 0 & 85.3 & $<0.01$ \\
\hline Ciprofloxacin & 65 & 35 & 71.4 & 28.6 & 67.6 & $>0.5$ \\
\hline Enrofloxacin & 65 & 35 & 67.9 & 32.1 & 66.2 & $>0.5$ \\
\hline Nitrofurantoin & 42.5 & 57.5 & 96.4 & 3.6 & 64.7 & $<0.01$ \\
\hline Levofloxacin & 47.5 & 52.5 & 75 & 25 & 58.8 & $<0.01$ \\
\hline Kanamicin & 15 & 85 & 85.7 & 14.3 & 44.1 & $<0.01$ \\
\hline Nalidixic acid & 17.5 & 82.5 & 60.7 & 39.3 & 35.3 & $<0.01$ \\
\hline Gentamicin & 5 & 95 & 71.4 & 28.6 & 32.4 & $<0.01$ \\
\hline Ticarcillin & 0 & 100 & 39.3 & 60.7 & 16.2 & $<0.01$ \\
\hline Ceftriaxone & 12.5 & 87.5 & 21.4 & 78.6 & 16.2 & $0.5>\mathrm{p}>0.1$ \\
\hline Cefixime & 7.5 & 92.5 & 17.9 & 82.1 & 11.8 & $>0.1$ \\
\hline Piperacillin & 0 & 100 & 25 & 78 & 10.3 & $<0.01$ \\
\hline Cefotaxime & 0 & 100 & 14.3 & 85.7 & 5.9 & $<0.01$ \\
\hline Cephalexin & 0 & 100 & 14.3 & 85.7 & 5.9 & $<0.01$ \\
\hline Cefoxitin & 2.5 & 97.5 & 3.6 & 96.4 & 2.9 & $>0.5$ \\
\hline Cloxacillin & 0 & 100 & 3.6 & 96.4 & 1.5 & $0.5>\mathrm{p}>0.1$ \\
\hline Ampicillin & 0 & 100 & 3.6 & 96.4 & 1.5 & $0.5>\mathrm{p}>0.1$ \\
\hline Penicillin & 0 & 100 & 0 & 100 & 0 &.-- \\
\hline Cephradine & 0 & 100 & 0 & 100 & 0 & --- \\
\hline Cephalothin & 0 & 100 & 0 & 100 & 0 & --- \\
\hline Carbencillin & 0 & 100 & 0 & 100 & 0 & --- \\
\hline
\end{tabular}




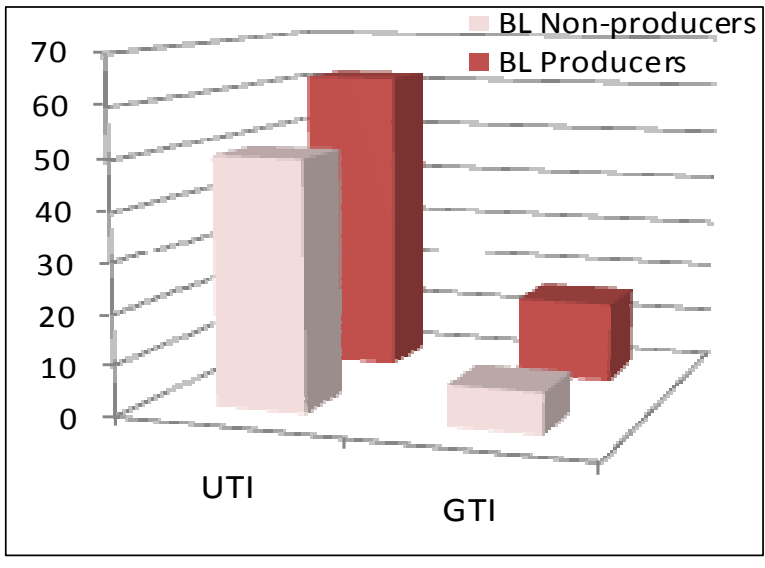

Figure (1): Beta lactamase enzyme distribution in urinary and genital tract isolates.

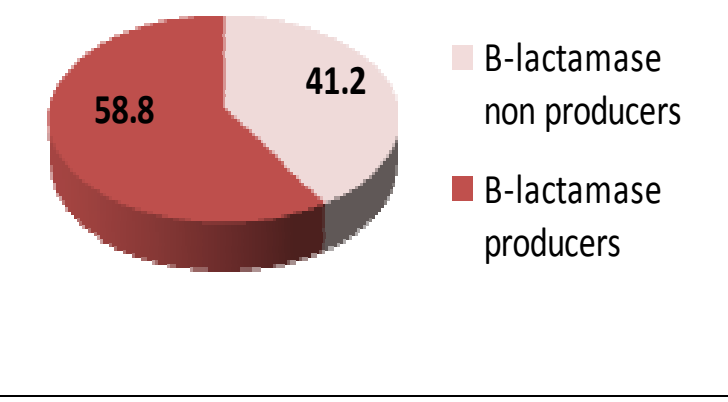

Figure (2): B-lactamase production in Ecoli isolates.

\section{Discussion}

ESBLs have been detected worldwide, and they are forming a major contributor of drug resistance in many Enterobacteriaceae ${ }^{(14)}$.

In the present work the ESBL E. coli was detected in $58.8 \%$ of our isolates which is in accordance with results of other studies that ranged between $41 \%-68 \%^{(3,10,15-18)}$. Another study done in a Turkish Hospital has reported a higher percentage $(79.3 \%)^{(19)}$, while other researchers reported a lower percentages of such isolates ranging between (11.4-38.2\%) $(1,4,7,11,20)$.

The prevalence of ESBLs among clinical isolates varies greatly in different geographical areas and are rapidly changing over time ${ }^{(14)}$. This variation may be attributed to the difference in the use of antibiotics between different localities particularly B-lactam antibiotics.
Broad spectrum resistance, in the current study, was detected in $98.5 \%$ of E. coli isolates, which was somewhat relative to the result of study ${ }^{(5)}$ done in Iran where $87.9 \%$ of the isolated $\mathrm{E}$. coli were found to have a broad spectrum resistance.

Extended spectrum B-lactam resistant E. coli was recorded in $16.2 \%$ of the isolates. Such finding is in contrast with the results of another work $^{(5)}$, where $45.2 \%$ of their isolates found to be ESBL resistant. However in Pakistan a lower result $(8 \%)$ was reported ${ }^{(3)}$.

Multi drug resistance (MDR) is a major problem in the management of uropathogens. It has been noticed that the clinical isolates of E. coli that are ESBL producers are more likely to be resistant to other non $\beta$-lactam antimicrobial agents. This MDR may be due to plasmid carrying several genes coding multiresistance which are transferred from one bacterium to another. The future treatment of MDR ESBL producing $E$. coli may become more complex because of further limitations of the available drugs.

In the present work, MDR ESBL formed $25 \%$ of the isolates, where all are $\beta$-lactamase producers. Aminzadeh, et $\mathrm{al}^{(5)}$ in Iran also reported $25 \%$ to be MDR E. coli $^{(5)}$. Other studies reported much higher percentages of MDR ESBL-E. coli $(69.6 \% \text { and } 90.5 \%)^{(4,11)}$. Actually determination of the resistance pattern can help in great deal to select the best antibiotic in such a situation.

Actually, a statistical significant difference $(p<0.05)$ was found in the susceptibility profile between ESBL producers and non ESBL producing $\mathrm{E}$. coli for amikacin, nitrofurantoin, levofloxacin, kanamicin, nalidixic acid, gentamicin, ticarcilin, piperacillin, and cefotaxime. These findings support the hypothesis that extended spectrum ESBL producing strains of $E$. coli are more likely to have diminished susceptibility to non betalactam antibiotics compared to non betalactamase producing $\mathrm{E}$. coli ${ }^{(21)}$. Hence, the antimicrobial susceptibility profile of the individual isolates should be used to guide treatment.

Penicillins are bactericidal agents that inhibit the bacterial cell wall synthesis. In this study 
the resistance of the isolated $E$. coli to penicillin and ampicillin was $100 \%$. Similar results were reported too by other studies ${ }^{(5)}$ particularly among the $\beta$-lactamase producers. This low susceptibility to penicillins may be due to the continuous use of these drugs for many years. Moreover, earlier other studies ${ }^{(22)}$ reported that ampicillin has no more effect on urinary tract pathogens.

The cephalosporins particularly second and third generations are generally used for the treatment of E.coli infections. Sensitivity to ceftriaxone in this study was detected only in $16.2 \%$ which was lower than that reported in other studies $(28.1 \%, 50 \%$ and $24 \%){ }^{(4,5,17)}$. Furthermore the resistance to cefotaxime and cephalexin was $94.1 \%$ in non $\beta$-Ictamase producers, while in B-lactamase producers it was $100 \%$, which is in agreement with the result of another work by Jirachai, et $\mathrm{al}^{(23)}$. This high resistance to cephalosporins could be explained by the fact that in our locality these drugs are easily available from pharmacy without doctor prescription and are relatively inexpensive antibiotics. Also, inadequate doses of these agents are sometimes used for treatment of different types of infections which may result in the development of high degree of resistance.

Flouroquinolones are particularly useful for the treatment of UTI because a high concentration of the drug in the urine can be achieved. The sensitivity to ciprofloxacin in the present work was observed in $67.6 \%$ of the isolated $\mathrm{E}$. coli which was in agreement with other studies ${ }^{(4,5,17,23)}$. The sensitivity to levofloxacin among B-lactamase nonproducers was $75 \%$ which is similar to that reported by Jirachai and his co-workers (73\%) (23).

Concerning aminoglycosides, they are generally prescribed against infections caused by gram negative bacilli. Amikacin really showed a high sensitivity percentage $(85 \%)$, which is in agreement with the findings of other researchers ${ }^{(1,5,11,18,20)}$, while other studies $^{(10,17,24)}$ revealed a lower sensitivity which may be due to the extensive use of this drug in those localities. Also, the sensitivity to gentamicin was $61.7 \%$ which is similar to that reported by other studies ${ }^{(1,23,25)}$.

In conclusion, $E$. coli isolates recovered from clinical specimens in this region produced Blactamase in high percentage, they are resistant to penicillins and most cephalosporins and the MDR was higher among the B-lactamase producers. Therefore strict antibiotic policy should be adopted in hospitals to estimate the impact of higher resistance in bacteria and to take steps for reducing this resistance. Knowledge of the resistance pattern in a geographical area will help to guide appropriate antibiotic use, and screening for ESBL production as a routine procedure in clinical laboratories which may give a valuable information to the clinician in appropriate selection of antibiotics.

\section{References}

1. Chlebicki M. P, HML Oh. ESBL in clinical isolates of E. coli and Klebsiella spp. In a Singapore hospital. Annals Academy of Medicine 2004; 33(3): 302-306.

2. Washington WJ, Stephen A, William J, et al. In: Koneman's color Atlas and Textbook of Diagnostic Microbiology. Bacterial resistance to antimicrobial agents. Lippincott, Williams and Wilkins. $6^{\text {th }}$ ed. 2006: 945-1020.

3. Ali A. M, Rafi S, Qureshi AH. Frequency of ESBL producing gram negative bacilli among clinical isolates at clinical laboratories of army medical college, Rawalpindi. J Ayub Med Coll Abbottabad. 2004; 16(1):35-7.

4. Iroha I.R, Adikwu M.U, Esimone C.O, et al. $\mathrm{ESBL}$ in $\mathrm{E}$. coli isolated from a tertiary hospital in Enugu state, Nigeria. Pak J Med Sci 2009; 25 (2): 279-282.

5. Aminzadeh $Z$, Sadat $M$, Shabani $M$. Bacteriuria by ESBL producing $E$. coli and Klebsiella pneumoiae. Iranian Journal of Kidney Diseases 2008;2(4):197-200.

6. David ML and Derek FJ. Detection of Blactamase mediated resistance. Journal of antimicrobial chemotherapy 2001; 48 (S1): 59-64.

7. Methee C, Pichai J, Anuwat K, et al. Epidemiology of ESBL producing Gram negative Bacilli at Siriraj Hospital, 
Thailand, 2003. South Asian J Trop Med Public Health 2005; 36(6):1503- 1509.

8. Johann DD, Christine $\mathrm{C}$, Euqene W. Antimicrobial resistance with focus on Blactam resistance in Gram negative bacilli. American Journal of Medicine. 1997;103(1):51-59.

9. Muller $M$, McGreen $A$. Variation in approach to ESBL Enterobacteriaceae among infection control practitioners. Canada communicable disease report 2002; 28(15):121-4.

10. Shashikala S, Kavith R, Gireesh AR, Shamsul KPM. Routine screening for ESBL production, A necessity of today. The internet journal of microbiology 2007; 3(1).

11. Supriya S, Suresh V, Sarfraz A, et al. Evaluation of ESBL in urinary isolates. Indian J Med Res. 2004; 120(6): 553-559.

12. Collee JG, Fraser AG, Marimion BP et al. In: Practical Medical Microbiology. Enterobacteriaceae. PB Crichton. Churchill Livingstone 1996: 361-384.

13. Collee JG, Fraser AG, Marimion BP et al. In: Practical Medical Microbiology. Laboratory control of antimicrobial therapy. RS Miles, SGB Amyes. Churchill Livingstone 1996: 151-178.

14. Livermore DM. B-lactamases in Laboratory and clinical resistance. Clin Microbiol Rev 1995; 8:557-584.

15. Albertini MJ. Surveillance of methicillin resistant Staphylococcus aureus (MRSA) and Enterobacteriaceae producing extended spectrum beta - Lactamase (ESBL) in Northern France: a five year Multicentre prevalence study. J Horp Infect 2002; 52(2):107-13.

16. Anthony D.H, Jessina C. M, Judith A. J, et al. Risk factors for colonization with ESBL producing bacteria and intensive care unit admission. EID Journal 2007;13(8):11449.
17. Sasirekha B, Manasa R, Ramya $P$, et al. Frequency and antimicrobial sensitivity pattern of ESBL producing $\mathrm{E}$. coli and Klebsiella pneumoniae isolated in a tertiary care hospital. Al Ameen J Med Sci 2010; 3(4):265- 271.

18. BabypadmIni S, Appalaraju B. ESBL in urinary isolates of $\mathrm{E}$. coli and Klebsiella pneumoniae prevalence and susceptibility pattern in a tertiary hospital. IJMM 2004; 22(3):172-174.

19. Hosoglu S, Gundes S, Kolayli F, et al. ESBL in ceftazidime-resistant $\mathrm{E}$. coli and Klebsiella pneumoniae in Turkish hospitals. IJMM. 2007; 25(4):346-350.

20. Daoud Z, Hakime N. Prevalence and susceptibility patterns of ESBL-producing E. coli and Klebsiella pneumoniae in a general hospital in Beiurut, Lebanon. Rev Esp Quimioterap, 2003; 16(2):233-238.

21. Shafaq AH, Sayed SJ, Mustafa K. Occurrence of MDR and ESBL producing E. coli causing UTI. Journal of Basic and Applied Sciences 2011;7(1):39-43.

22. Sahm DF, Thorsberry C, Mayfeild DC, et al. MDR urinary tract isolates of E.coli, Prevention and patients demographics in the United States in 2000. Antimicrob Agents Chemoth. 2001; 35:236-239.

23. Jirachai W, Kamonwon J, Wacharee J. The prevalence and Susceptibility patterns of ESBL-producing Klebsiella pneumoniae and E. coli in Chonburi Hospital. J Infect Dis Antimicrob agents. 2006;23(2):57-63.

24. Husam S.K, Khalid M. B, Abiola C. S, et al. ESBL in E. coli and Klebsiella pneumoniae. J Infect Dev Ctries 2009; 3(4):295-299.

25. Abdulla A K and Kumar A. Prevalence and antimicrobial susceptibility of ESBLproducing E. coli and Klebsiella pneumoniae in a general hospital. Ann Saudi Med 2005; 25(3):239-242. 